\title{
Prescribing Patterns for Acute Respiratory Infections in Children in Primary Health Care Centers, Makkah Al Mukarramah, Saudi Arabia
}

\author{
M.H. Shaheen ${ }^{1, *}$, M.I. Siddiqui ${ }^{2}$, H.A. Jokhdar ${ }^{2}$, A. Hassan-Hussein ${ }^{2}$, M.A. Garout ${ }^{2}$, S.M. Hafiz ${ }^{1}$, \\ M.M. Alshareef ${ }^{1}$, A.M. Falemban ${ }^{1, \oplus}$, A.A. Neveen ${ }^{1}$, A.A. Nermeen ${ }^{1}$ \\ ${ }^{1}$ Faculty of Medicine, Umm Al-Qura University, Makkah, Saudi Arabia \\ ${ }^{2}$ Department of Community Medicine, Umm Al-Qura University, Makkah, Saudi Arabia
}

\section{ARTICLE INFO}

Article History

Received 23 July 2017

Accepted 24 October 2017

\begin{abstract}
Acute respiratory infections (ARI) are a major public health problem and one of the commonest reasons for visiting primary health care centers (PHC). In developing countries, seventy-five percent of the cases are treated with antibiotics, although the majority are caused by viral infection. Our aim was to observe the pattern of physician practices with respect to ARI, in comparison to WHO protocols and to provide recommendations for health promotion enhancement. The study was conducted in Makkah PHC centers, for 2 months. A total 14 PHC centers were randomly selected. And 908 prescriptions were obtained randomly from general practitioners (GP) and analyzed. We found that males were 522 and females were and 386 . Weights were not recorded in $224(24.7 \%)$ cases. In 87 cases $(9.6 \%)$ no diagnosis was recorded. In $515(62.34 \%)$ of cases, antibiotics were prescribed; most of these cases were of simple common cold, with antibiotics not recommended. To conclude, many physicians in Makkah are not following the WHO guidelines for Acute Respiratory Infection. Educational health programs should be conducted to sensitize the physicians regarding the appropriate method of diagnosis and rational use of antibiotics.
\end{abstract}

(C) 2018 Atlantis Press International B.V. This is an open access article under the CC BY-NC license (http://creativecommons.org/licences/by-nc/4.0/).

\section{INTRODUCTION}

Acute respiratory infections (ARI) are considered one of the foremost public health problems [1] and are the leading cause for morbidity and mortality in several developing countries [2]. They have been estimated to cause $18-33 \%$ of all deaths of children below five years. Half of deaths in developing countries is among children under five years of age [3]; this is 10-50 times more than developed countries with the same ARI cause [4]. Acute respiratory infections (ARI) in children constitute approximately $30-60 \%$ of PHC visits around the world; they cause $20-30 \%$ of hospital admissions [5]. At least one respiratory virus is found in $15 \%$ of hospitalized children [6]. Pneumonia is responsible for more deaths of children than other illnesses - more than HIV, malaria and measles combined [7]. In addition, it is one of the commonest reasons for visits to the primary care physician [8]. The prevalence of acute respiratory infection in children is $24 \%$ in Saudi Arabia [9]. The causes for ARIs vary from self-limiting conditions such as the common cold to the more serious bacterial pneumonia. Even though the majority of cases are viral [10-12], three-quarters of antibiotics consumed are for ARIs, which has contributed to the emergence of drug-resistant bacterial pathogens, serious side effects, and a significant waste of health care resources [8]. An important concern is the inappropriate use of antibiotics for non-bacterial infections and for self-limiting clinical conditions [13]. The prescription of

* Corresponding author. Email: M1shaheen1@gmail.com antibiotic in primary health care centers (PHC) is high [14]. Some of the studies reported antibiotic prescription as high as, $66 \%$, $58.8 \%$ and $56 \%$ [15-18]. Despite the very fact that the majority infections treated at this level of care are of self-limiting in nature [19-21], there's an overuse of antimicrobial treatments [22-24]. Therefore, assessing healthcare providers prescribing patterns is essential, as there is limited data regarding this issue [25].

Another matter of concern is of prescribed antibiotic [26-29]. This has serious consequences: exposing the patients to adverse effects, increase of number of visits for mild issues [14,26,30], and development of resistant bacterium strains [14,31]. Infections caused by resistant bacterium are related to bigger morbidity and mortality rates, and health care resources wasting. [30,32].

The World Health Organization (WHO) has developed a protocol for the management of ARI, particularly for developing countries such as Saudi Arabia, the protocol includes the revised recommendations: A) Children with fast breathing pneumonia with no chest in drawing or general danger sign should be treated with oral amoxicillin. B) Children age 2-59 months with chest in drawing pneumonia should be treated with oral amoxicillin C) Children aged 2-59 months with severe pneumonia should be treated with parenteral ampicillin (or penicillin) and gentamicin as a first-line treatment. D) Ampicillin (or penicillin when ampicillin is not available) plus gentamicin or ceftriaxone are recommended as a first-line antibiotic regimen for HIV-infected and -exposed infants and for children under 5 years of age with chest in drawing pneumonia or severe pneumonia. 
E) Empiric cotrimoxazole treatment for suspected Pneumocystis jirovecii (previously Pneumocystiscarinii) pneumonia (PCP) is recommended as an additional treatment for HIV-infected and -exposed infants aged from 2 months up to 1 year with chest in drawing or severe pneumonia. F) Empirical cotrimoxazole treatment for Pneumocystis jirovecii pneumonia (PCP) is not recommended for HIV-infected and -exposed children over 1 year of age with chest in drawing or severe pneumonia. [33]. This study was conducted to observe the pattern of physicians' prescriptions, to determine their practices related to ARI management and compliance with WHO protocols, and to provide recommendations to enhance their practices in primary health care centers.

\section{METHODS}

\subsection{Study Setting}

The study was conducted in Primary Health Care Centres (PHC) of Makkah Al Mukarramah, Saudi Arabia.

\subsection{Study Design}

A cross-sectional study, conducted from 1/2/2016 to 31/3/2016.

\subsection{Sample Size}

The sample size was calculated using the online software of Epi Info, developed by the Centers for Disease Control and Prevention (CDC), using a confidence level of $95 \%$. As our technique was cluster sampling we chose a design effect of 2.0. The estimated sample size was 769. An additional 20\% (154) was added to account for dropouts, because of possibility of refusal of any PHC physician to participate in the study with a final total of 923. (For details please, see Appendix A below).

\subsection{Sampling Procedure}

The sampling technique used was Multistage cluster sampling, to select PHC centers during the first phase of the study, then to select registered physicians in the second phase of the study and then later to select their prescriptions. After obtaining the list of all PHC centers of Makkah from the Ministry of Health, we randomly selected $20 \%$ of the PHC centers with the help of Statistical Package for the Social Sciences software (SPSS) version 21. As there are 70 PHC centers in Makkah, a total 14 PHC centers were selected. From each selected PHC center we randomly selected general practitioners and from each physician we randomly selected their prescriptions for ARI. After obtaining their consent, a total of 908 prescriptions were collected by going to clinic daily and collecting the prescriptions. We compared the prescriptions with WHO guidelines recommendations for acute respiratory infections [33]. The main variables assessed, beside basic demographic characteristics, included: chief complaints, temperature, pulse rate, respiratory rate, provisional diagnosis and the type of antibiotic prescribed. All variables were entered into the computer and analyzed by SPSS version 21 .

The protocol was submitted to IRB of College of Medicine and ethical approval was obtained as HAPO-02-K-012-2016-02-142.

\section{RESULTS}

A total of 923 prescriptions were planned, whereas 908 prescriptions were collected, as one of the physician refused to participate in the study. The majority of children, 558/908 (61.5\%), were seen in public PHC centers and 350/908 (38.5\%) of them were in private PHC centers. By gender, more than half of the cases were males i.e. 522/908 (57.5\%) and females accounted for 386/908 (42.5\%). (Table 1).

The predominant categories of age were from 1 to 5 years $(289 / 908$, $31.8 \%)$ and $6-10$ years $(258 / 908,28.4 \%)$ (Table 1$)$.

Table 1 Profile of children presenting to PHCs with acute resiratory infection, Makkah, KSA, 2016

\begin{tabular}{|c|c|c|}
\hline Variables & Number of cases & Percentage (\% \\
\hline \multicolumn{3}{|l|}{ Age (Years) } \\
\hline Less than 1 & 69 & $(7.6 \%)$ \\
\hline $1-5$ & 289 & $(31.8 \%)$ \\
\hline $6-10$ & 258 & $(28.4 \%)$ \\
\hline $11-15$ & 161 & $(17.7 \%)$ \\
\hline $16-18$ & 131 & $(14.4 \%)$ \\
\hline More than 18 & 0 & $(0 \%)$ \\
\hline \multicolumn{3}{|l|}{ Gender } \\
\hline Male & 522 & $(57.5 \%)$ \\
\hline Female & 386 & $(42.5 \%)$ \\
\hline \multicolumn{3}{|l|}{ Type of center } \\
\hline Public & 558 & $(61.5 \%)$ \\
\hline Private & 350 & $(38.5)$ \\
\hline \multicolumn{3}{|l|}{ Chief complaint } \\
\hline Fever & 120 & $120(13.2 \%)$ \\
\hline Cough & 75 & $75(8.3 \%)$ \\
\hline Runny nose & 24 & $24(2.6 \%)$ \\
\hline Sore throat & 13 & $13(1.4 \%)$ \\
\hline More than one respiratory symptom & 569 & $569(62.7 \%)$ \\
\hline Others & 68 & $(7.5 \%)$ \\
\hline Not written & 39 & $(4.3 \%)$ \\
\hline \multicolumn{3}{|l|}{ Physical examination } \\
\hline Congested throat & 121 & $(13.3 \%)$ \\
\hline Ear problems & 51 & $(5.6 \%)$ \\
\hline Pharyngeal tonsillar erythema & 99 & $(10.9 \%)$ \\
\hline Tonsillar exudate & 35 & $(3.9 \%)$ \\
\hline More than one respiratory finding & 188 & $(20.7 \%)$ \\
\hline Others & 55 & $(6.1 \%)$ \\
\hline Not written & 359 & $(39.5 \%)$ \\
\hline \multicolumn{3}{|l|}{ Clinical diagnosis } \\
\hline $\begin{array}{l}\text { Pneumonia with tachypnea, with no } \\
\text { costal retractions or general danger } \\
\text { signs }\end{array}$ & 15 & $(1.7 \%)$ \\
\hline Pneumonia with costal retractions & 5 & $(0.6 \%)$ \\
\hline Severe pneumonia & 1 & $(0.1 \%)$ \\
\hline Common cold & 227 & $(25.0 \%)$ \\
\hline Upper respiratory tract infection & 103 & $(11.3 \%)$ \\
\hline Allergic asthma & 11 & $(1.2 \%)$ \\
\hline Tonsillitis and pharyngitis & 35 & $(3.9 \%)$ \\
\hline Bronchial asthma & 11 & $(1.2 \%)$ \\
\hline Pharyngitis & 123 & $(13.5 \%)$ \\
\hline Lower respiratory tract infection & 9 & $(1.0 \%)$ \\
\hline Tonsillitis & 104 & $(11.5 \%)$ \\
\hline Otitis media & 56 & $(6.2 \%)$ \\
\hline Otitis externa & 10 & $(1.1 \%)$ \\
\hline Bronchitis & 51 & $(5.6 \%)$ \\
\hline Bronchiolitis & 12 & $(1.3 \%)$ \\
\hline Influenza & 17 & $(1.9 \%)$ \\
\hline Others & 48 & $(5.3 \%)$ \\
\hline Not written & 70 & $(7.7 \%)$ \\
\hline Total & 908 & $(100 \%)$ \\
\hline
\end{tabular}


Chief complaints were recorded in 869/908 (95.7\%) cases. Most common single chief complaint was fever in 120/869 (13.8\%), cough in $75 / 869(8.6 \%)$, rhinorrhea in $24 / 869(2.7 \%)$, and sore throat in $13 / 869(1.4 \%)$ cases. More than one respiratory symptom was recorded in 569/869 (65.4\%), and other complaints formed $68 / 869(7.8 \%)$ of all cases. (Table 1) Unfortunately, only $550 / 908(60.5 \%)$ of the paediatric patients were physically examined. Physical examination findings demonstrated: congested throat in $121 / 550(22 \%)$, ear problems were found in 51/550 (9.3\%), pharyngeal tonsillar erythema in 99/550 (18\%) tonsillar exudate in $35 / 550(6.4 \%)$, more than one respiratory finding in $188 / 550$ (34.2\%), other findings were found in 55/550 (10\%) cases (Table 1).

Diagnosis was recorded in 838/908 (92.3\%) of cases, with the most common diagnosis being common cold at 227/838 (27.6\%), followed by $123 / 838$ cases of pharyngitis (15\%), 104/838 Tonsillitis $(12.6 \%)$ and pneumonia in only $21 / 838$ cases $(2.4 \%)$. Other diagnoses were noted in $346 / 838$ (42.1\%) of cases (Table 1).

Pneumonia with tachypnea, without costal retractions or general danger signs, were noted in $15 / 21$ cases $(71.4 \%)$, pneumonia with costal retractions in $5 / 21$ cases $(23.8 \%)$ and only $1 / 21$ child suffered from severe pneumonia (4\%) (Table 1$)$.

$684 / 908(75.3 \%)$ of patients had their weights recorded during their visit. Of the three main vital signs, heart rate was recorded in $602 / 908(66.3 \%)$, temperature in $764 / 908(84.1 \%)$ and respiratory rate in $582 / 908(64.1 \%)$ (Table 2$)$.

Overall, antibiotics were prescribed in 515/908 cases $(56.7 \%)$, distributed as either a single therapy in 103/515 (20\%), a combination of antibiotic and antipyretics in 164/515 (31.8\%), or as antibiotics with other drugs in 248/515 (48.1\%) (Fig. 1).

Table 2 Distribution of the recording of various variables required to support a diagnosis

\begin{tabular}{lcc}
\hline Features recorded & Yes & No \\
\hline Weight & $684(75.3 \%)$ & $224(24.7 \%)$ \\
Temperature & $764(84.1 \%)$ & $144(15.9 \%)$ \\
Heart rate & $602(66.3 \%)$ & $306(33.7 \%)$ \\
Respiratory rate & $582(64.1 \%)$ & $326(35.9 \%)$ \\
Chief complaints & $869(95.7 \%)$ & $39(4.3 \%)$ \\
Physical examination & $550(60.6 \%)$ & $358(39.4 \%)$ \\
Provisional diagnosis & $838(92.3 \%)$ & $70(7.7 \%)$ \\
\hline
\end{tabular}

First choice of antibiotic prescribed was Amoxicillin in 275/515 (53.3\%) of cases, second choice was Ceftriaxone in 81/515 (15.7\%), followed by Augmentin in 45/515 (8.7\%), various other antibiotics in $90 / 515$ (17.5\%), and lastly more than one antibiotic was prescribed in $14 / 515$ cases (2.7\%) (Fig. 2).

\section{DISCUSSION}

In the PHC of Makkah, the incidence of ARI in children under 5 years old was 358 (39.4\%). Several studies had a similar incidence of approximately $30-40 \%$ in children below 5 years - Al-Khalidi, Ramani, and Peasah $[8,34,35]$. In contrast, Siddiqui found an ARI incidence of $83.2 \%$ [7].

In the majority of studies, including ours, ARI cases consisted of upper respiratory tract infections (URTI). Lower respiratory tract infections (LRTI), such as pneumonia, bronchitis and bronchiolitis, were $10 \%$ in our study as well as in Al-Khalidi, and Saeed $[8,34]$. Sarfraz [25] reported a higher respiratory tract infections rate of $68 \%$.

This study, as well as most other studies, found patients, predominantly, of male gender: Siddiqui, Al-Khalidi, Krishnan, and Dharmage [7,8,34,36,37], in contrast to Acharya [4] where both genders were equivalent. Chandwani [38] reported a maledominated society as a possible reason.

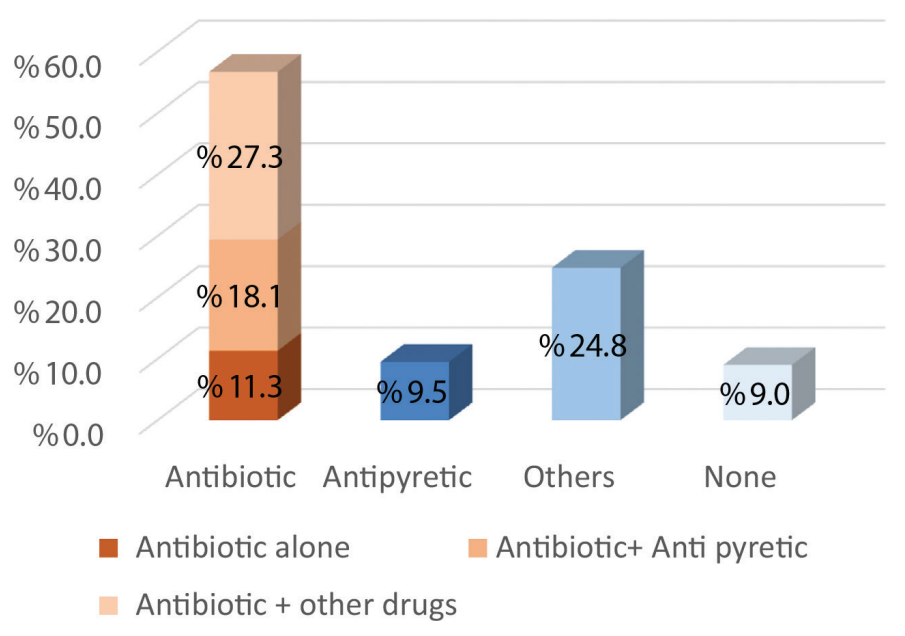

Figure $1 \mid$ Distribution of choice of children's treatment

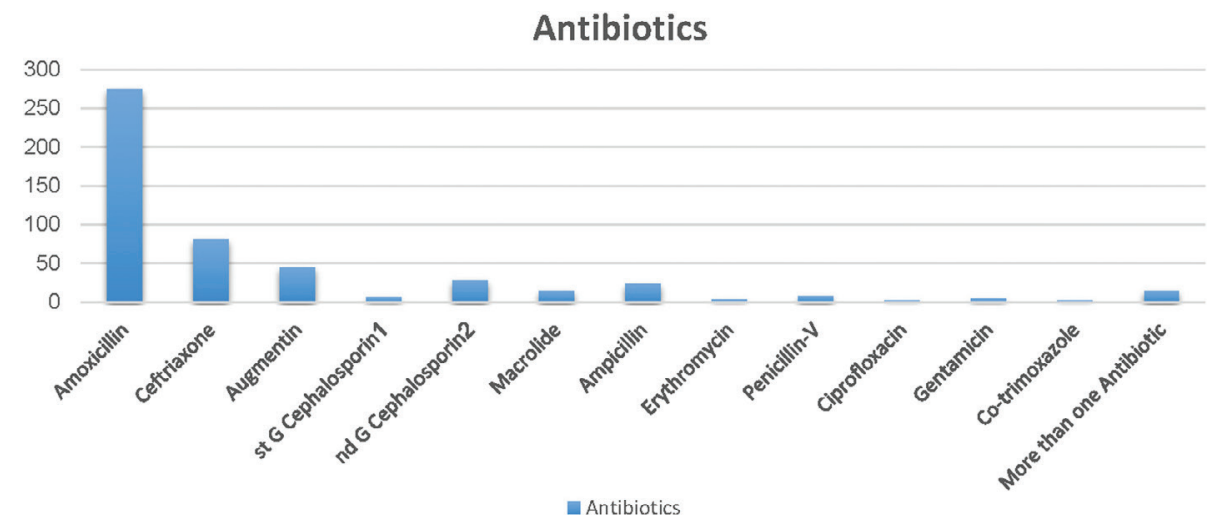

Figure 2 Distribution of the types of antibiotics used 
$569(65.4 \%)$ patients presented with more than one respiratory symptom. The single most common complaint was fever, seen in 120 cases $(13.8 \%)$, with a similar rate reported by Siddiqui [7] and Chandwani [21]. A much higher rate of $98.8 \%$ was found in Ramani [34]. Al-Khaldi [8] reported 70\% of cases complained of cough.

Vital signs were recorded in this study and in Siddiqui [7] as follows: Temperature 144 (15.9\%), 106(52\%); Heart rate 306 (33.7\%), 177(88\%); Respiratory rate 326 (35.9\%), 135(67\%); and Weight 224 (24.7\%), 132(65\%), respectively. Al-Khaldi [8] and Ramani [34] did not mention these variables.

Congested throat was the most frequent finding in this study and Al-Khaldi [8]. Interestingly, the rank order of the most common diagnoses was similar between this study and that of Al-Khaldi [8]: Common cold was first $(27.6 \%, 42 \%)$, followed by pharyngitis $(15 \%, 25 \%)$, and tonsillitis $(12.6 \%, 17 \%)$, respectively. This may be due to physician habits within the same nation.

Diagnosis was written in the great majority of PHC cases, in $92.3 \%$, similar to Al-Khaldi [8] at $97.5 \%$. In contrast, in Siddiqui [7] the diagnosis was written in less than half of the cases (44.6\%).

The drug of choice was Amoxicillin in 275 (53.3\%) of cases, followed by Ceftriaxone in 81 (15.7\%), and Augmentin in 45 $(8.7 \%)$ cases. One of the reason of prescribing, antibiotic other than amoxicillin, as observed by us, was non-availability of amoxicillin, in some of the centers. Siddiqui [7] reported the most common antibiotic prescribed as Amoxicillin in 21.4\%, followed by a first generation cephalosporin (19.9\%) and co-trimoxazole (14.3\%). A recent study in Morocco by Jroundi [39] found the most commonly prescribed antibiotic was a cephalosporin $(213 / 286 ; 74.5 \%)$, followed by macrolides $(21 \%)$, then Gentamicin (13.6\%). Al-Khaldi [8] did not report antibiotic classes. According to revised WHO guidelines, Amoxicillin should be given as first line of treatment and Ceftriaxone as second line of treatment [33].

Our study limitation is the duration of sample collection; it was conducted at the end of the local winter season because of late approval from ethical committee.

\section{CONCLUSION}

Many physicians in Makkah Al Mukarramah are not following the WHO guidelines for Acute Respiratory Infection. Educational health programs should be conducted to sensitize the physicians as well as patients regarding the appropriate method of diagnosis and rational use of antibiotics [40].

\section{ETHICAL CONSENT}

The consent of practitioners were sought before obtaining the prescriptions.

\section{CONFLICT OF INTEREST}

The authors declare no potential conflicts of interest with respect to research, authorship and/or publication of this manuscript.

\section{ACKNOWLEDGEMENTS}

The authors are grateful to Bashar Omar Babkour, Haneen Salah Al-Masoudi, Noura Awad Almalki and Marya Abdurrahman Alqithami for their role in data collection.

\section{APPENDIX A. SAMPLE SIZE FOR FREQUENCY IN A POPULATION}

Population size (for finite population correction factor or $\mathrm{fpc}$ ) (N): 1600000

Hypothesized \% frequency of outcome factor in the population (p): $50 \% \pm 5$

Confidence limits as \% of 100 (absolute $\pm \%)(d): 5 \%$

Design Effect (for cluster surveys-DEFF): 2

Sample $\operatorname{Size}(n)$ for Various Confidence Levels.

\begin{tabular}{cc}
\hline Confidence level (\%) & Sample size \\
\hline $95 \%$ & 769 \\
$80 \%$ & 329 \\
$90 \%$ & 542 \\
$97 \%$ & 942 \\
$99 \%$ & 1327 \\
$99.9 \%$ & 2165 \\
$99.99 \%$ & 3026 \\
\hline
\end{tabular}

Sample size $\boldsymbol{n}=\left[\operatorname{DEFF}^{\star} \mathbf{N p}(\mathbf{1}-\mathbf{p})\right] /\left[\mathbf{d}^{2} / \mathbf{Z}_{1-\alpha / 2}^{2}{ }^{\star}(\mathbf{N}-1)+\mathbf{p}^{\star}(\mathbf{1}-\mathbf{p})\right]$

Results from OpenEpi, Version 3, open source calculator-SSPropor Print from the browser with ctrl-P

or select text to copy and paste to other programs.

\section{REFERENCES}

[1] Francis NA, Butler CC, Hood K, Simpson S, Wood F, Nuttall J. Effect of using an interactive booklet about childhood respiratory tract infections in primary care consultations on reconsulting and antibiotic prescribing: a cluster randomised controlled trial. BMJ 2009;339;b2885.

[2] UNICEF | The State of World Children 2013 [http://www.unicef. org/sowc2013/].

[3] Reddaiah V, Kapoor SK. Acute respiratory infections in rural underfives. Indian J Pediatr 1988;55;424-6.

[4] Acharya D, Prasanna K, Nair S, Rao R. Acute respiratory infections in children: a community based longitudinal study in South India. Indian J Public Health 2002;47;7-13.

[5] Mitra NK. A longitudinal study on ARI among rural under fives. Indian J Community Med 2001;26;8-11.

[6] Wang H, Zheng Y, Deng J, Wang W, Liu P, Yang F, et al. Prevalence of respiratory viruses among children hospitalized from respiratory infections in Shenzhen, China. Virol J 2016;13;1.

[7] Siddiqui MI, Baloch AA, Ahmed SI, Jafri SIA. Audit of prescribing patterns of doctors for the management of acute respiratory infections in children. Elective Med J 2014;2;6-9.

[8] Al-Khaldi YM, Diab MM, Al-Gelban KS, Al-Asmari AS, Al-Amin S, Al-Shahrani MS. Prescribing patterns for acute respiratory 
infections in primary health care, aseer region, Saudi Arabia. J Family Community Med 2005;12;121-6.

[9] Saeed AA, Bani IA. Prevalence and correlates of acute respiratory infections in children less than two years of age. Saudi Med J 2000;21;1152-6.

[10] van Gageldonk-Lafeber AB, Heijnen M-LA, Bartelds AI, Peters MF, van der Plas SM, Wilbrink B. A case-control study of acute respiratory tract infection in general practice patients in The Netherlands. Clin Inf Dis 2005;41;490-7.

[11] Dyar OJ, Beović B, Vlahović-Palčevski V, Verheij T, Pulcini C. How can we improve antibiotic prescribing in primary care? Expert Rev Anti-infective Therapy 2016;14;403-13.

[12] Urrusuno RF, Dorado MF, Arenas AV, Martino CS, Baena SC, Balosa MCM. Improving the appropriateness of antimicrobial use in primary care after implementation of a local antimicrobial guide in both levels of care. Eur J Clin Pharmacol 2014;70;1011-20.

[13] Nash DR, Harman J, Wald ER, Kelleher KJ. Antibiotic prescribing by primary care physicians for children with upper respiratory tract infections. Arch Pediatr Adolesc Med 2002;156;1114-9.

[14] Goossens H, Ferech M, Vander Stichele R, Elseviers M, Group EP. Outpatient antibiotic use in Europe and association with resistance: a cross-national database study. The Lancet 2005;365;579-87.

[15] Petersen I, Hayward AC. Antibacterial prescribing in primary care. J Antimicrobial Chemother 2007;60;i43-i7.

[16] Serna M, Ribes E, Real J, Galván L, Gascó E, Godoy P. High exposure to antibiotics in the population and differences by sex and age. Aten Primaria 2011;43;236-44.

[17] Lallana-Alvarez MJ, Feja-Solana C, Armesto-Gomez J, Bjerrum L, Rabanaque-Hernandez MJ. Outpatient antibiotic prescription in Aragón and the differences by gender and age. Enferm Infecc Microbiol Clin 2012;30;591-6.

[18] Holloway KA, Ivanovska V, Wagner AK, Vialle-Valentin C, RossDegnan D. Prescribing for acute childhood infections in developing and transitional countries, 1990-2009. Paediatr Int Child Health 2015;35;5-13.

[19] Arroll B. Antibiotics for upper respiratory tract infections: an overview of Cochrane reviews. Respir Med 2005;99;255-61.

[20] Smith SM, Fahey T, Smucny J, Becker LA. Antibiotics for acute bronchitis. Cochrane Database Syst Rev 2004;4.

[21] Puhan MA, Vollenweider D, Latshang T, Steurer J, Steurer-Stey C. Exacerbations of chronic obstructive pulmonary disease: when are antibiotics indicated? A systematic review. Respir Res 2007;8;30.

[22] Ong DS, Kuyvenhoven MM, Van Dijk L, Verheij TJ. Antibiotics for respiratory, ear and urinary tract disorders and consistency among GPs. J Antimicrob Chemother 2008;62;587-92.

[23] Llor C, Cots J, Gaspar M, Alay M, Rams N. Antibiotic prescribing over the last 16 years: fewer antibiotics but the spectrum is broadening. Eur J Clin Microbiol Infect Dis 2009;28;893-7.

[24] Adriaenssens N, Coenen S, Versporten A, Muller A, Minalu G, Faes C, et al. European Surveillance of Antimicrobial Consumption (ESAC): outpatient antibiotic use in Europe (1997-2009). J Antimicrob Chemother 2011;66 Suppl 6;vi3-vi12.

[25] Sarfraz T. Acute respiratory infections in children. Pak Armed Forces Med J 1996;46;28-32.
[26] Ojeniran M, Shouval R, Miskin IN, Moses AE, Shmueli A. Costs of appropriate and inappropriate use of antibiotics in the emergency department. IMAJ-Israel Med Assoc J 2010;12;742.

[27] Murphy M, Bradley CP, Byrne S. Antibiotic prescribing in primary care, adherence to guidelines and unnecessary prescribing-an Irish perspective. BMC Family Pract 2012;13;43.

[28] Martínez MA, Inglada L, Ochoa C, Villagrasa JR. Treatments SSGoA. Assessment of antibiotic prescription in acute urinary tract infections in adults. J Infect 2007;54;235-44.

[29] Tobia CC, Aspinall SL, Good CB, Fine MJ, Hanlon JT. Appropriateness of antibiotic prescribing in veterans with community-acquired pneumonia, sinusitis, or acute exacerbations of chronic bronchitis: a cross-sectional study. Clin Ther 2008;30;1135-44.

[30] Lee C-C, Lee C-H, Chuang M-C, Hong M-Y, Hsu H-C, Ko W-C. Impact of inappropriate empirical antibiotic therapy on outcome of bacteremic adults visiting the ED. Am J Emerg Med 2012;30;1447-56.

[31] Costelloe C, Metcalfe C, Lovering A, Mant D, Hay AD. Effect of antibiotic prescribing in primary care on antimicrobial resistance in individual patients: systematic review and meta-analysis. BMJ 2010;340;c2096.

[32] Butler CC, Hillier S, Roberts Z, Dunstan F, Howard A, Palmer S. Antibiotic-resistant infections in primary care are symptomatic for longer and increase workload: outcomes for patients with E. coli UTIs. Br J Gen Pract 2006;56;686-92.

[33] Revised WHO classification and treatment of pneumonia in children at health facilities: evidence summaries, 2014.

[34] Ramani VK, Pattankar J, Puttahonnappa SK. Acute Respiratory Infections among Under-Five Age Group Children at Urban Slums of Gulbarga City: A Longitudinal Study. J Clin Diagn Res 2016;10;LC08.

[35] Peasah SK, Purakayastha DR, Koul PA, Dawood FS, Saha S, Amarchand R, et al. The cost of acute respiratory infections in Northern India: a multi-site study. BMC Public Health 2015;15;1.

[36] Krishnan A, Amarchand R, Gupta V, Lafond KE, Suliankatchi RA, Saha S, et al. Epidemiology of acute respiratory infections in children-preliminary results of a cohort in a rural north Indian community. BMC Infect Dis 2015;15;1.

[37] Dharmage SC, Rajapaksa LC, Fernando DN. Risk factors of acute lower respiratory tract infections in children under five years of age. Southeast Asian J Trop Med Public Health 1996;27;107-10.

[38] Chandwani H, Pandor J. Healthcare-Seeking Behaviors of Mothers regarding their Children in a Tribal Community of Gujarat, India. Electron Physician 2015;7;990.

[39] Jroundi I, Benmessaoud R, Mahraoui C, Moraleda C, Tligui H, Seffar M, et al. Antibiotic usage prior and during hospitalization for clinical severe pneumonia in children under five years of age in Rabat. Morocco Antibiotics 2013;2;450-64.

[40] Md Rezal RS, Hassali MA, Alrasheedy AA, Saleem F, Md Yusof FA, Godman B. Physicians' knowledge, perceptions and behaviour towards antibiotic prescribing: a systematic review of the literature. Exp Rev Anti-infective Ther 2015;13;665-80. 